\title{
AN X-RAY DIFFRACTION STUDY OF MICROSTRUCTURAL DEFORMATION INDUCED BY CYCLIC LOADING OF SELECTED STEELS
}

$$
\text { CONF-9606178-- }
$$

P. M. Fourspring and R. N. Pangborn

June 1996

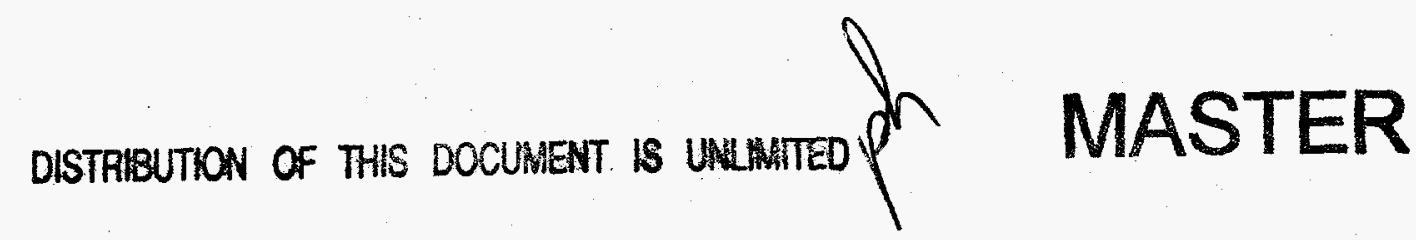

\section{NOTICE}

This report was prepared as an account of work sponsored by the United States Government. Neither the United States, nor the United States Department of Energy, nor any of their employees, nor any of their contractors, subcontractors, or their employees, makes any warranty, express or implied, or assumes any legal liability or responsibility for the accuracy, completeness or usefulness of any information, apparatus, product or process disclosed, or represents that its use would not infringe privately owned rights.

Operated for the U. S. Department of Energy by KAPL, Inc. a Lockheed Martin company 


\section{DISCLAIMER}

This report was prepared as an account of work sponsored by an agency of the United States Government. Neither the United States Government nor any agency thereof, nor any of their employees, make any warranty, express or implied, or assumes any legal liability or responsibility for the accuracy, completeness, or usefulness of any information, apparatus, product, or process disclosed, or represents that its use would not infringe privately owned rights. Reference herein to any specific commercial product, process, or service by trade name, trademark, manufacturer, or otherwise does not necessarily constitute or imply its endorsement, recommendation, or favoring by the United States Government or any agency thereof. The views and opinions of authors expressed herein do not necessarily state or reflect those of the United States Government or any agency thereof. 


\section{DISCLAIMER}

Portions of this document may be illegible in electronic image products. Images are produced from the best available original document. 
Patrick M. Fourspring ${ }^{1}$ and Robert N. Pangborn ${ }^{2}$

An X-Ray Diffraction Study of Microstructural Deformation Induced by Cyclic Loading of Selected Steels

REFERENCE: Fourspring, P. M., Pangborn, R. N., "An X-Ray Diffraction Study of Microstructural Deformation Induced by Cyclic Loading of Selected Steels," Fatigue and Fracture Mechanics: 28th Volume, ASTM STP 1321, J. H. Underwood and B. D. Macdonald, M. R. Mitchell, Eds., American Society for Testing and Materials, 1997.

ABSTRACT: X-ray double crystal diffractometry (XRDCD) was used to assess cyclic microstructural deformation in a face centered cubic (fcc) steel (AISI304) and a body centered cubic (bcc) steel (SA508 class 2). The first objective of the investigation was to determine if XRDCD could be used to effectively monitor cyclic microstructural deformation in polycrystalline Fe alloys. A second objective was to study the microstructural deformation induced by cyclic loading of polycrystalline $\mathrm{Fe}$ alloys. The approach used in the investigation was to induce fatigue damage in a material and to characterize the resulting microstructural deformation at discrete fractions of the fatigue life of the material. Also, characterization of microstructural deformation was carried out to identify differences in the accumulation of damage from the surface to the bulk, focusing on the following three regions: near surface $(0-10 \mu \mathrm{m})$, subsurface $(10-300 \mu \mathrm{m})$, and bulk. Characterization of the subsurface region was performed only on the AISI304 material because of the limited availability of the SA508 material. The results from the XRDCD data indicate a measurable change induced by fatigue from the initial state to subsequent states of both the AISI304 and the SA508 materials. Therefore, the XRDCD technique was shown to be sensitive to the microstructural deformation caused by fatigue in steels; thus, the technique can be used to monitor fatigue damage in steels. In addition, for the AISI304 material, the level of cyclic microstructural deformation in the bulk material was found to be greater than the level in the near surface material. In contrast, previous investigations have shown that the deformation is greater in the near surface than the bulk for $\mathrm{Al}$ alloys and bcc Fe alloys.

KEY WORDS: fatigue damage, cyclic microstructural deformation, X-ray diffraction, X-ray double crystal diffractometry, AISI304, stainless steel, SA508, pressure vessel steel

Prior to fatigue crack nucleation, microstructural deformation occurs in an engineering material as the result of cyclic loading. X-ray diffraction is one of several techniques that have been used and are being used to assess cyclic microstructural deformation. This information can be used to monitor fatigue damage and, as a result, to enhance the safety and the economy of a wide range of mechanical components and structures. In addition, an understanding of the response of a material to cyclic loading can be used to develop materials that are more resistant to fatigue damage.

\footnotetext{
${ }^{1}$ Engineer, Lockheed Martin Corporation, POB 1072, Schenectady, NY 12301-1072.

2Professor of Engineering Mechanics, The Pennsylvania State University, 101 Hammond Building, University Park, PA 16802.
} 
In the past, various X-ray diffraction techniques have been used successfully to assess cyclic microstructural deformation in $\mathrm{Al}, \mathrm{Ni}$, and $\mathrm{Fe}$ alloys. Furthermore, one technique, that uses a double crystal diffractometer to assess this deformation, has been proposed for and validated on aircraft structural alloys ( $\mathrm{Al}$ alloys) and aircraft engine alloys ( $\mathrm{Ni}$ alloys). To build on these results, X-ray double crystal diffractometry (XRDCD) was used in the investigation reported in this paper to assess cyclic microstructural deformation in a face centered cubic (fcc) steel (AISI304) and a body centered cubic (bcc) steel (SA508 class 2).

The objective of this investigation was twofold. The first objective was to determine if XRDCD could be used to effectively monitor cyclic microstructural deformation in polycrystalline Fe alloys. The second objective was to study the microstructural deformation induced by cyclic loading of polycrystalline Fe alloys.

\section{TECHNICAL BASIS}

Cyclic loading induces microstructural deformation in a material prior to the subsequent nucleation of microcracks that lead to macrocrack formation and propagation to failure. The first step in the fatigue failure process, microcrack initiation, comprises three critical processes [1-9]:

1. cyclic microstructural deformation,

2. near surface deformation, and

3. microcrack nucleation.

Microcrack initiation begins with the microstructural deformation of a material in response to cyclic loading. This deformation, referred to as cyclic microstructural deformation, results in dislocations, either existing or generated, rearranging into lower strain energy states. The resulting dislocation configurations decrease the ductility of the material by hampering dislocation motion [10]. Microstructural deformation in the near surface $(0-10 \mu \mathrm{m})$ and the subsurface $(10-300 \mu \mathrm{m})$ region develops differently than in the bulk as a result of the influence of the free surface. This unique deformation leads to geometric discontinuities that can become localized stress risers on the microstructural scale. Therefore, the decreased ductility together with the localized stress risers results in microcrack nucleation. At these geometric discontinuities, microcracks nucleate as a result of the inability of the microstructure to relax the strain energy that rises as a result of the discontinuity.

During cyclic microstructural deformation, groups of interacting dislocations evolve from random clusters within volumes that are nearly free of dislocations to bands of interacting dislocations surrounding volumes that are nearly free of dislocations. For cubic materials, the following three general categories of dislocation configurations have been observed and evolve in the order shown[1-9]:

1. dislocation patches and planar arrays,

2. walls and channels (including the labyrinth variation), and

3. cells.

Furthermore, cyclic microstructural deformation will lead to a change in the dislocation density from the initial density. Several microstructural processes can increase or decrease the dislocation density. For example, if the initial dislocation density is insufficient to accommodate the imposed cyclic loading, then dislocation regeneration can lead to an increase in the dislocation density allowing the material to accommodate the loading. The initial dislocation density varies with the fabrication process. A cold worked material will have a high dislocation density, and an annealed material will have a low dislocation density.

$\mathrm{X}$-ray diffraction is sensitive to cyclic microstructural deformation in engineering materials [11-23]. In general, the level of lattice distortion in the diffracting grains 
changes the shape of the X-ray diffraction profiles. XRDCD can provide additional information by indicating the formation of cell dislocation configurations with multimodal diffraction peaks. For example, if the initial state of a material is annealed, then cyclic loading will most likely increase lattice distortion and lead to the formation of cell dislocation configurations. The increase in the lattice distortion is caused by the increase in the dislocation density from dislocation regeneration. As a result, the diffraction peaks will, in general, "broaden" and become multimodal.

\section{EXPERIMENTAL APPROACH AND PROCEDURES}

The objective of the experimental investigation was to induce fatigue damage in selected materials and to characterize the resulting microstructural deformation at discrete fractions of the fatigue life. Characterization of microstructural deformation was also carried out to identify differences in the accumulation of damage from the surface to the bulk. In the near surface region $(0-10 \mu \mathrm{m})$, the procedure was to interrupt the cyclic loading of the test bars at various estimated fractions of life and then characterize the near surface of the test bars at each interruption. Once the test bar failed and the number of cycles to failure became known, the exact fraction of life at each interruption was calculated by dividing the number of cycles at each interruption by the total number of cycles at failure. For the study of the subsurface region $(10-300 \mu \mathrm{m})$, the procedure was to halt the cyclic loading of the test bars at various estimated fractions of life and then characterize the surface of the test bars. A layer of material was removed from the surface by electropolishing to permit characterization of the newly exposed surface. Therefore, by repeating this procedure several times at varying depths into the material, a profile of the microstructural deformation within the subsurface region emerged. Finally, for the bulk characterization, the Ishikawajima-Harima Heavy Industries Company (IHI) provided samples from fatigued test bars as part of a parallel research project [24]. IHI exposed the bulk material by cutting the gage section of the test bars perpendicular to the longitudinal axis to produce disk shaped samples.

The experimentation included two different steels. One steel was an annealed austenitic stainless steel, AISI304, that is widely used in power systems for piping and piping support structures. The second steel was a quenched and tempered, vacuum treated alloy steel, SA508, class 2, that is used for nuclear reactor pressure vessels. Figure 1 contains a sketch of the test bar configuration, and Table 1 provides a description of the composition, heat treatment, surface preparation, and cyclic loading for each material. The microstructure of the AISI304 is face centered cubic (fcc) austenite, and the microstructure of the SA508 is a body centered cubic (bcc) granular bainite. Microscopy showed that the grain size of the AISI304 was approximately 80 to $90 \mu \mathrm{m}$ and the grain size of the SA508 was approximately 10 to $20 \mu \mathrm{m}$. For both materials, an electropolishing procedure insured a smooth surface and removed any near surface microstructure deformation caused by machining.

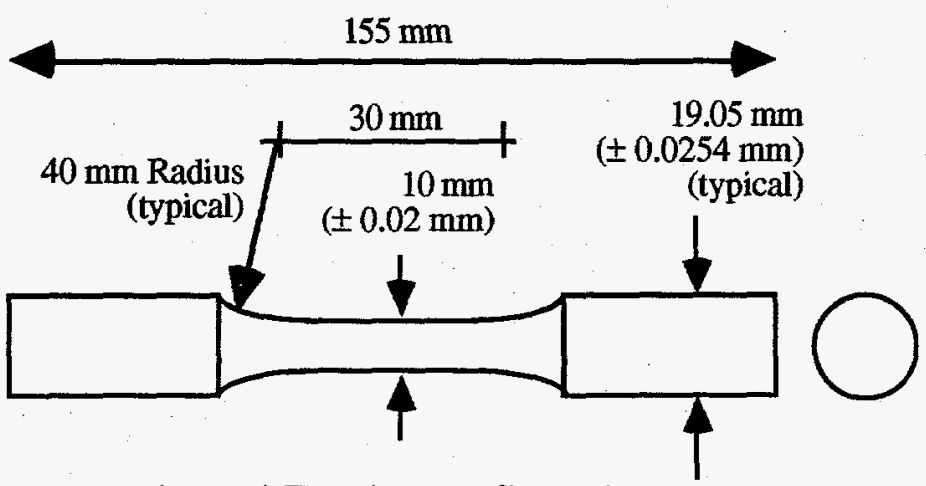

Figure 1 Test bar configuration 
Table 1 Composition, Heat Treatment,, Surface Preparation, and Cyclic Loading

\begin{tabular}{|c|c|}
\hline AISI304 & SA508 class 2 \\
\hline \multicolumn{2}{|c|}{$\overline{\text { Composition }}$} \\
\hline $\begin{array}{l}\text { (test bars) } 0.052 \% \mathrm{C} ; 1.64 \% \mathrm{Mn} ; 0.36 \% \mathrm{Si} ; \\
18.48 \% \mathrm{Cr} ; 9.10 \% \mathrm{Ni} ; 0.027 \% \mathrm{P} ; 0.022 \% \mathrm{~S} \\
\text { (samples) } 0.04 \% \mathrm{C} ; 1.09 \% \mathrm{Mn} ; 0.67 \% \mathrm{Si} \\
18.87 \% \mathrm{Ci} ; 8.73 \% \mathrm{Ni} ; 0.034 \% \mathrm{P} ; 0.009 \% \mathrm{~S}\end{array}$ & $\begin{array}{l}\text { (test bars and samples) } 0.21 \% \mathrm{C} ; \\
1.53 \% \mathrm{Mn} ; 0.08 \% \mathrm{P} ; 0.03 \% \mathrm{~S} ; 0.28 \% \mathrm{Si} \\
1.02 \% \mathrm{Ni} ; 0.21 \% \mathrm{Cr} ; 0.53 \% \mathrm{Mo} ; 0.004 \% \mathrm{~V}\end{array}$ \\
\hline \multicolumn{2}{|c|}{ Heat Treatment } \\
\hline $\begin{array}{l}\text { (test bars) Annealing: } 1060^{\circ} \mathrm{C} \text { in Argon } \\
\text { Environment for } 60 \text { minutes; Quenching: } \\
\text { room temperature in Argon Environment } \\
\text { for } 60 \text { minutes } \\
\text { (samples) Annealing: } 1060^{\circ} \mathrm{C} \text { in air for } 54 \\
\text { minutes; Quenching: water }\end{array}$ & $\begin{array}{l}\text { (test bars and samples) Normalizing: } 890- \\
905^{\circ} \mathrm{C} / 12.3 \mathrm{hrs} \text {; A Air Cool; Tempering: } \\
645-650^{\circ} \mathrm{C} / 12.5 \mathrm{hrs} \text {; Furnace Cool; } \\
\text { Reheating } 870-890^{\circ} \mathrm{C} / 6.5 \mathrm{hrs} . ; \text { Water } \\
\text { Quench; Tempering: } 650-670^{\circ} \mathrm{C} / 6.5 \mathrm{hrs} \text {; } \\
\text { Furnace Cool; Stress Relieving: } 608- \\
631^{\circ} \mathrm{C} / 45.4 \mathrm{hrs} \text {; Furnace Cool }\end{array}$ \\
\hline \multicolumn{2}{|c|}{ Surface Preparation } \\
\hline $\begin{array}{l}\text { (test bars) Electropolish: Hydrite } 4000^{\mathrm{TM}} \\
\left(50 \% \mathrm{H}_{3} \mathrm{PO}_{4} \& 50 \% \mathrm{H}_{2} \mathrm{SO}_{4} \text { ); }\right. \\
3.0 \text { amps/sq.in.; } 55-60^{\circ} \mathrm{C} \text {; time varied } \\
\text { (samples) Electropolish: } 100 \mathrm{ml} \mathrm{HClO}_{4} ; \\
400 \mathrm{ml} \text { Ethanol; } 1.785-7.65 \text { amps } / \mathrm{sq} \text {. in.; } \\
0-10^{\circ} \mathrm{C} ; 6 \text { minutes }\end{array}$ & 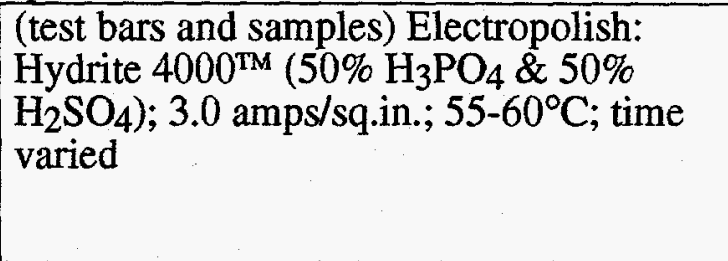 \\
\hline \multicolumn{2}{|c|}{ Cyclic Loading } \\
\hline $\begin{array}{l}\text { Strain Controlled with Extensometer; } \\
\text { Tension-Compression Load Ratio }(\mathrm{R}=-1) \text {; } \\
\text { Triangle Wave; Temperature: } 24^{\circ} \mathrm{C} ; \\
\text { Failure Criterion: } 10 \% \text { load drop } \\
\text { set1: } \Delta \varepsilon=0.60 \% ; 2 \mathrm{~Hz} \text { (test bars) } \\
\text { set1: } \Delta \varepsilon=0.60 \% ; 0.0833 \mathrm{~Hz} \text { (samples) } \\
\text { set2: } \Delta \varepsilon=1.20 \% ; 2 \mathrm{~Hz} \text { (test bars) }\end{array}$ & $\begin{array}{l}\text { Strain Controlled with Extensometer; } \\
\text { Tension-Compression Load Ratio (R=-1); } \\
\text { Triangle Wave; Temperature: } 300^{\circ} \mathrm{C} ; \\
\text { Failure Criterion: } 10 \% \text { load drop } \\
\text { set1: } \Delta \varepsilon=0.48 \% ; 2 \mathrm{~Hz} \text { (test bars) } \\
\text { set } 1: \Delta \varepsilon=0.48 \% ; 0.1042 \mathrm{~Hz} \text { (samples) } \\
\text { set2: } \Delta \varepsilon=0.78 \% ; 2 \mathrm{~Hz} \text { (test bars) } \\
\text { set2: } \Delta \varepsilon=0.78 \% ; 0.0641 \mathrm{~Hz} \text { (samples) }\end{array}$ \\
\hline
\end{tabular}

The X-ray double crystal diffractometer system used in the experimentation consisted of three primary components: an X-ray generator, a double crystal diffractometer, and a position sensitive, proportional X-ray detector. A Rigaku X-ray generator with a chromium target X-ray tube was used to reduce fluorescence from the steel specimens. A Blake Industries double crystal diffractometer with a silicon single crystal wafer of (111) orientation was employed to produce a parallel, monochromatic incident beam. An MBraun position sensitive, proportional X-ray detector intercepted the diffraction cone from the specimen and converted the X-ray intensities into electronic data. Auxiliary components in the X-ray double crystal system included a microcomputer for data acquisition and control and a stepping motor with a controller. Table 2 lists the XRDCD settings used for the test bars and the samples of both the AISI304 and the SA508 materials. For both materials, the approximate penetration depth of the $\mathrm{Cr}$ wavelength $\mathrm{X}$ rays for the planes characterized in this investigation is on the order of $10 \mu \mathrm{m}$. This value is based on the assumption that $95 \%$ of the incident intensity is reflected. 
Table 2 XRDCD Settings and Data Acquisition Regime

\begin{tabular}{|l|l|l|}
\hline \multicolumn{1}{|c|}{ Parameter } & \multicolumn{1}{|c|}{ AIS1304 } & \multicolumn{1}{c|}{ SA508 class 2 } \\
\hline \hline Plane & $(111)$ & $(110)$ \\
\hline X-ray Target & $\mathrm{Cr}, \mathrm{K} \alpha_{1} \mathrm{K \alpha}_{2}, 30 \mathrm{kV} / 15 \mathrm{~mA}$ & $\mathrm{Cr}, \mathrm{K} \alpha_{1} \mathrm{K \alpha} \alpha_{2}, 30 \mathrm{kV} / 15 \mathrm{~mA}$ \\
\hline First Crystal & Silicon single crystal, (111) & Silicon single crystal, (111) \\
\hline Beam Size & $3 \mathrm{~mm}$ horizontal & $3 \mathrm{~mm}$ horizontal \\
& $12 \mathrm{~mm}$ vertical for test bars & $12 \mathrm{~mm}$ vertical for test bars \\
& $10 \mathrm{~mm}$ vertical for samples & $8 \mathrm{~mm}$ vertical for samples \\
\hline $\begin{array}{l}\text { Detector Window } \\
\text { (per channel) }\end{array}$ & $0.5 \mathrm{~mm}$ horizontal & $0.5 \mathrm{~mm}$ horizontal \\
\hline Detector Distance & $0.0455 \mathrm{~mm}$ vertical & $0.0455 \mathrm{~mm}$ vertical \\
\hline Specimen Orientation & $85 \mathrm{~mm}$ (minimum) & $85 \mathrm{~mm}$ (minimum) \\
& Test Bars: vertical & Test Bars: vertical \\
& Samples: flat against holder & Samples: flat against holder \\
\hline Surface Locations & Two, 180 apart & Two, 180 apart \\
\hline Rotations per Surface & 80 at 4.1667 minutes each & 40 at 4.1667 minutes each \\
Location & & \\
\hline Dwell Time & 8 minutes & 8 minutes \\
\hline
\end{tabular}

\section{ANALYSES OF THE XRDCD DATA}

The two quantitative analyses of the XRDCD data were used in this investigation. The first method is referred to as the variance analysis, and the second method is referred to as the individual peak analysis. The same data sets were used in both analyses. The form of these data sets is a matrix of intensities of diffracted X-rays.

$\mathrm{XRDCD}$ allows the unique capability to analyze individual diffraction peaks from individual diffracting entities in a material. However, identification and deconvolution of the individual diffraction peaks require several mathematical operations. As a minimum, this analysis requires data smoothing to allow peak identification and peak modeling to allow deconvolution of overlapping peaks. Furthermore, the XRDCD data from materials with a very small grain size $(\approx 10 \mu \mathrm{m})$ have overlapping peaks that are difficult to model. As an alternative to individual peak analysis of the XRDCD data, an aggregate analysis of the same data provides a mathematically simple, but less sensitive approach. For this investigation, the variance of the XRDCD data was used as an aggregate parameter.

Variance is a statistical measure of the variability in data. As the diffraction peaks broaden or contract with the microstructural deformation in a material, the deviation of each data point from the mean intensity of all the data points will also change. The variance analysis of the XRDCD data involved normalizing the data to remove instrumental influences and calculating the statistical variance, specifically the sample variance, of the normalized data.

The individual peak analysis of the XRDCD data focuses on each diffraction peak within the data set instead of the data set as a whole. For assessing fatigue damage, the analysis of each peak is used in the traditional approach to analyze these data [11-18, 25]. These references refer to the individual peak analysis of the XRDCD data as computer aided rocking curve analysis (CARCA). The basic approach of the individual peak analysis is to identify an individual diffraction peak and to calculate a quantitative measure of the peak's shape, typically the integral breadth, as an indication of the microstructural deformation within the diffracting entity. 


\section{RESULTS}

The as-collected XRDCD data show discernible changes between the initial and the failure states for both the near surface and the bulk regions. Figures 2 and 3 display representative, as-collected XRDCD data from the fcc (AISI304) and the bcc (SA508) material, respectively. From the near surface region of the fcc material, Figure 2 shows a dramatic broadening of the diffraction peaks from the test bar cycled continuously to failure with an $1.20 \%$ strain range. As shown in Figure 3, the asperity of the diffraction peaks increases from the initial state to the failure state for the near surface region of the SA508 material cycled with a $0.78 \%$ strain range.

The results of the quantitative analyses of the XRDCD data provide coherent trends with accumulated fatigue damage and into the depth. The coherent trends indicate a measurable change induced by fatigue from the initial state to subsequent states. The trends in the results are juxtaposed with one another to allow comparison of the trends with the factors that were varied in the experimentation.

The results from the individual peak analysis of the XRDCD data are presented in two forms to emphasize the unique character of the XRDCD data that allows culling the undeformed diffracting entities (grains) from the deformed diffracting entities. First, Figure 4 shows representative histograms of the integral breadths from the bulk of the AISI304 material fatigued with a $0.60 \%$ strain range. These distributions show that some of the peaks, that is the diffracting entities, have remained unchanged while other peaks have broadened, increasing the magnitude of the integral breadth. Generally, the histograms indicate left skewed distributions for the initial state and early in the fatigue life; whereas, they indicate right skewed distributions for more advanced fatigue and the failure state. Second, Figures 5 and 6 show the trends in results from the individual peak analysis of the XRDCD data with accumulated fatigue damage from the near surface through the bulk. The population proportion estimator was used on the results of this analysis to quantify the change in the integral breadth distributions [26]. For this analysis, the estimator is the proportion of integral breadths that exceed 25 arc minutes. This value of the integral breadth is approximately the mean of all the integral breadths at the initial state. To test for statistical significance between the initial state of each test bar, or sample, and any subsequent state, the large sample $z$ test for population proportions was used. The null hypothesis used was $\mathrm{p}_{1}-\mathrm{p}_{2}=0$, and the significance level used was 0.05 . No results from the individual peak analysis for the SA508 materials were obtained, due to the difficulty in deconvoluting the small diffraction peaks.

The results from the variance analysis of the XRDCD data show coherent trends for both the fatigued fcc material (AISI304) and the fatigued bcc material (SA508). Figure 7 shows the results of the variance analysis for the bcc material. No statistical significance testing was completed on the variance estimator, since only two data points were available per state. Statistical significance testing is inappropriate with only two values of an estimator. 

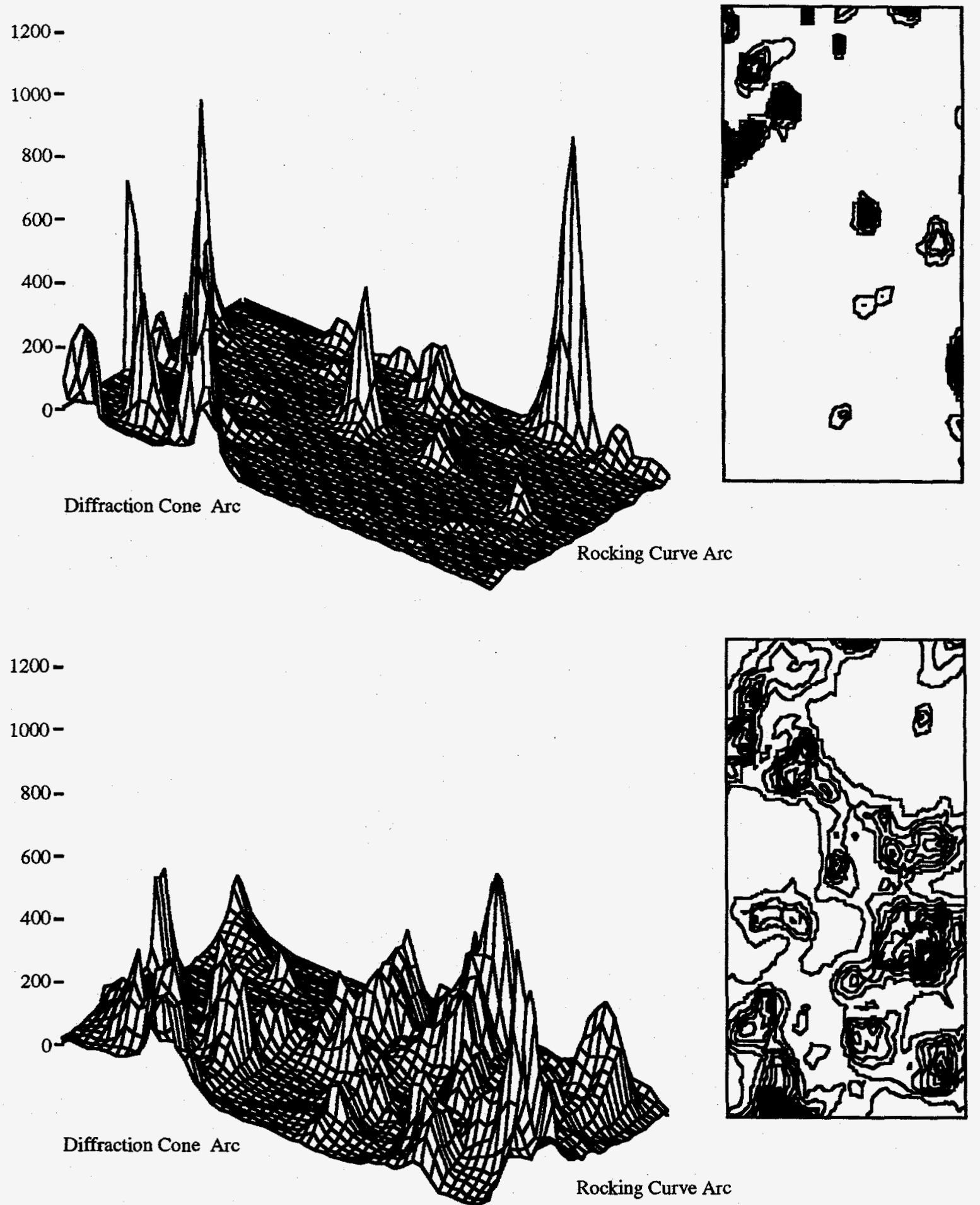

Figure 2 Surface and contour plots of XRDCD data: AISI $304, \Delta \varepsilon=1.20 \%$, near surface, top plots: initial state, bottom plots: failure state. range of axes: vertical: (as shown) total counts, diffraction cone Arc: $\approx 12^{\circ}$, rocking arc: $5.49^{\circ}$. 

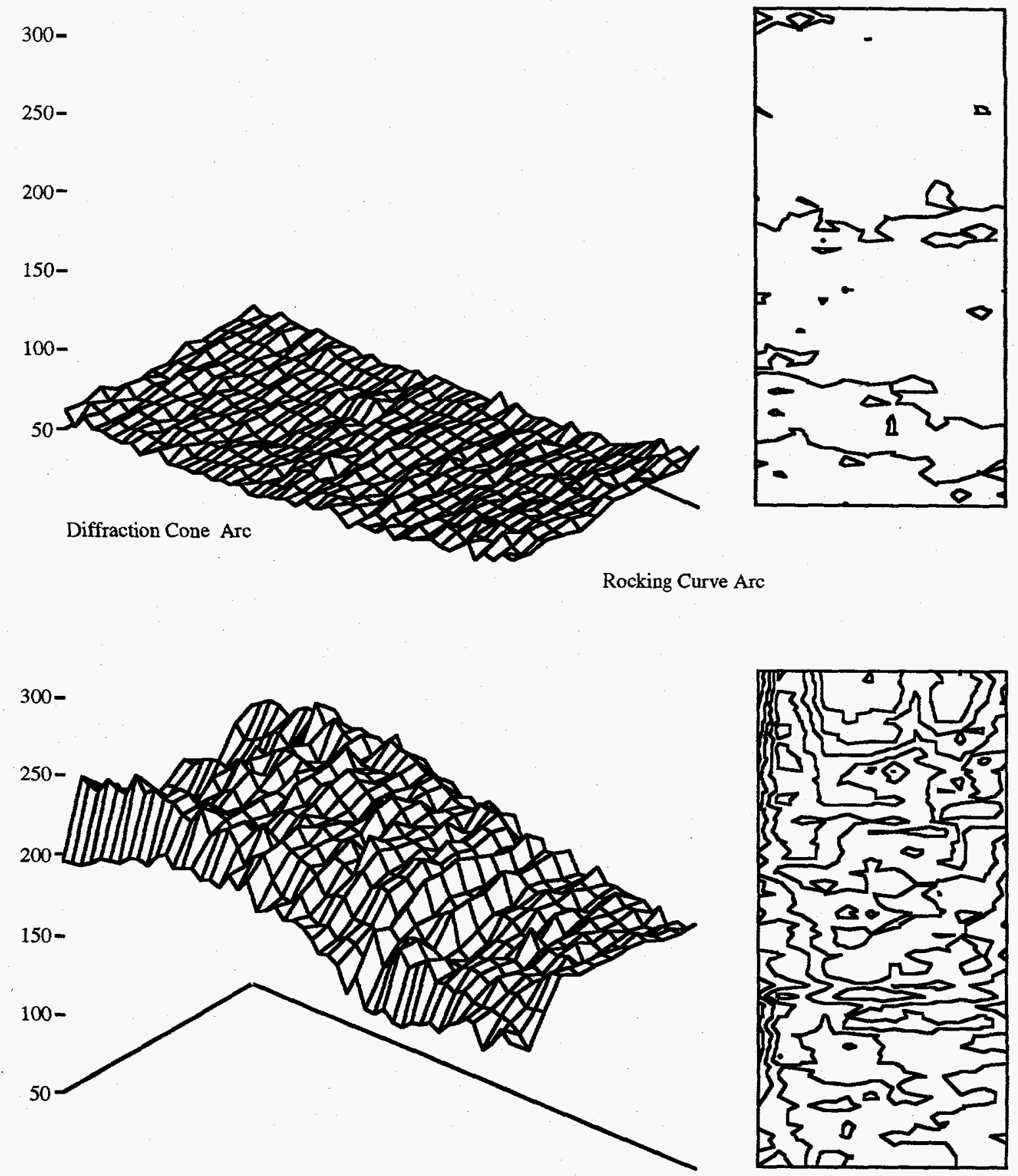

Diffraction Cone Arc

Rocking Curve Arc

Figure 3 Surface and contour plots of XRDCD data: SA508, $\Delta \varepsilon=0.78 \%$, near surface, top plots: initial state, bottom plots: failure state. range of axes: vertical: (as shown) total counts, diffraction cone arc: $\approx 12^{\circ}$, rocking arc: $1.647^{\circ}$. 

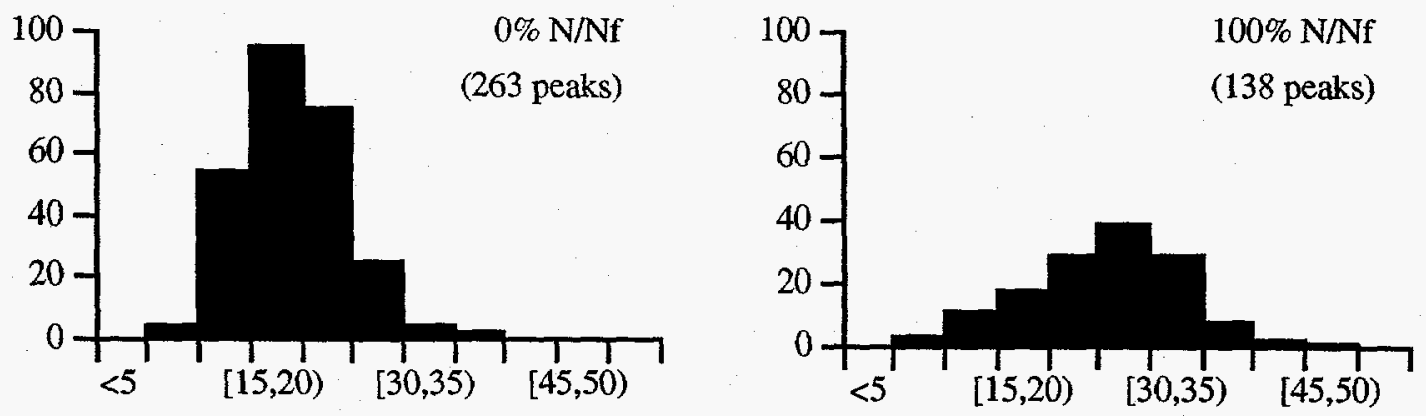

Figure 4 Histograms of the integral breadths from the XRDCD data.

AISI304, $\Delta \varepsilon=0.60 \%$, bulk

For all the trends from the quantitative analyses (Figures 5-7), the plots in the left column show the absolute magnitudes of the estimator (either proportional or variance); whereas, the plots in the right column show the value of the estimator normalized with a value that was based on the initial state estimator for the test bars or the samples. The absolute magnitudes are useful for comparing trends from the same analysis of other data. The relative magnitudes are useful for comparing the trends from various analyses, as well as from other studies, that use X-ray diffraction and other techniques to measure fatigue damage. To facilitate comparison between the results from the individual peak analysis and the variance analysis, the normalized values were equal either to the value of each estimator divided by the initial state value or vice versa; thus the normalized value always increased with accumulated damage or depth. The proportional estimator is unitless as is the normalized value of the estimator; therefore, the magnitudes plotted on the $y$ axes are unitless. The variance estimator is arbitrary as is the normalized value of the estimator; therefore, the magnitudes plotted on the $y$ axes are unitless. The appropriate units are shown on the $\mathrm{x}$ axes. For the proportional estimator, the solid symbols represent results which have a statistically significant difference from the initial state; and, the outlined symbols represent results which have no statistically significant difference from the initial state. The error bars indicate plus and minus one standard error and are only shown on the plots of the absolute magnitudes (plots in the left column). For the trends in the subsurface region (Figure 6), a horizontal line is shown to indicate the initial state of the material. This line is based on the initial state of the near surface region and implies that the initial state of the near surface represents the initial. state of subsurface and bulk regions. 

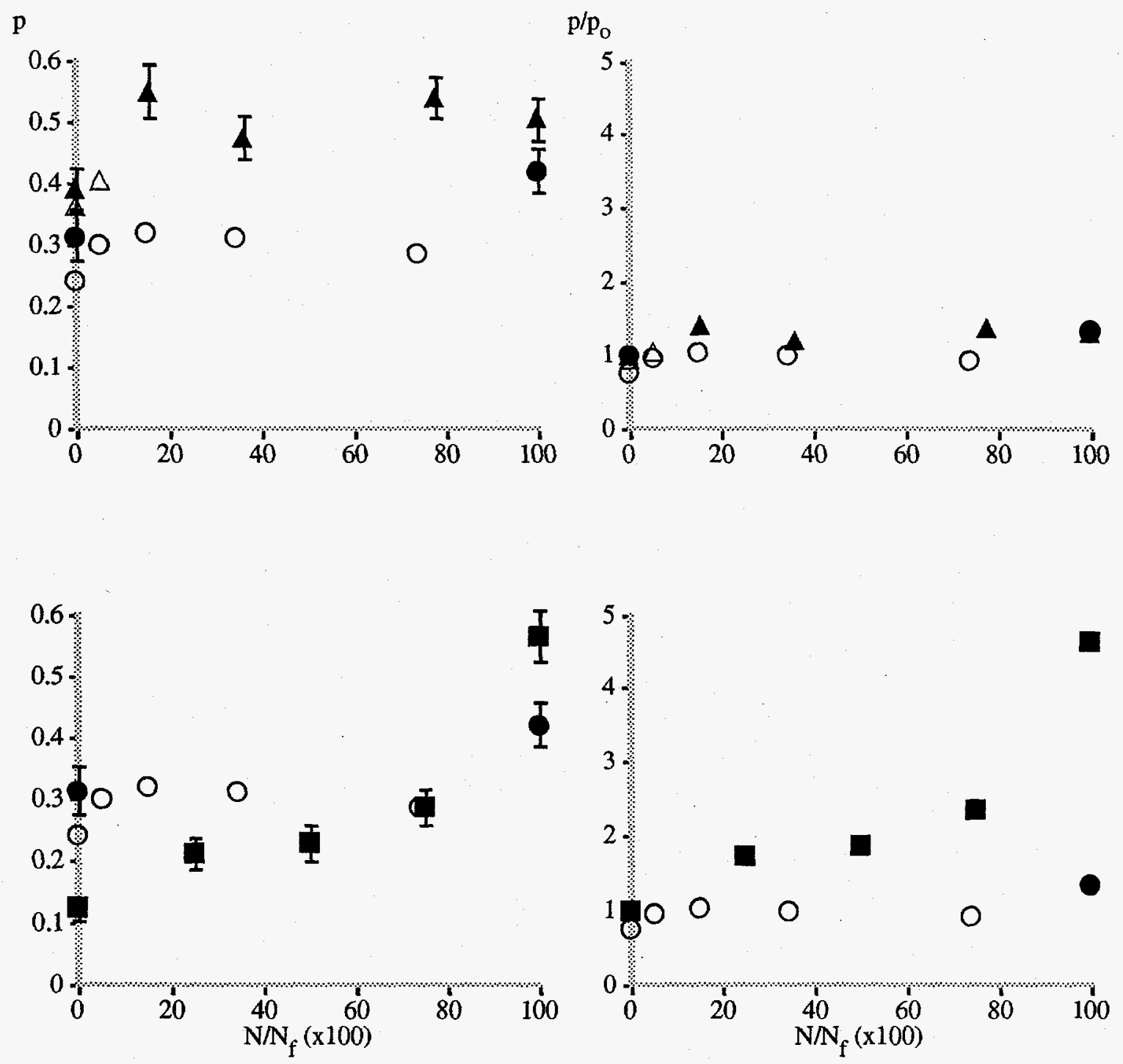

Figure 5 Individual peak analysis of the XRDCD data for AISI304. Comparison of the combined results from the $\Delta \varepsilon=0.60 \%$ and $\Delta \varepsilon=1.20 \%$ regimes (top) and the combined results from near surface and bulk for the $\Delta \varepsilon=0.60 \%$ regime (bottom).

(O) $\Delta \varepsilon=0.60 \%$ near surface, $\Delta(\Delta) \Delta \varepsilon=1.20 \%$ near surface, $\square$ ( $\square$ ( $\Delta \varepsilon=0.60 \%$ bulk. The solid symbols represent results which have a statistically significant difference from the initial state; and, the outlined symbols represent results which have no statistically significant difference from the initial state. 

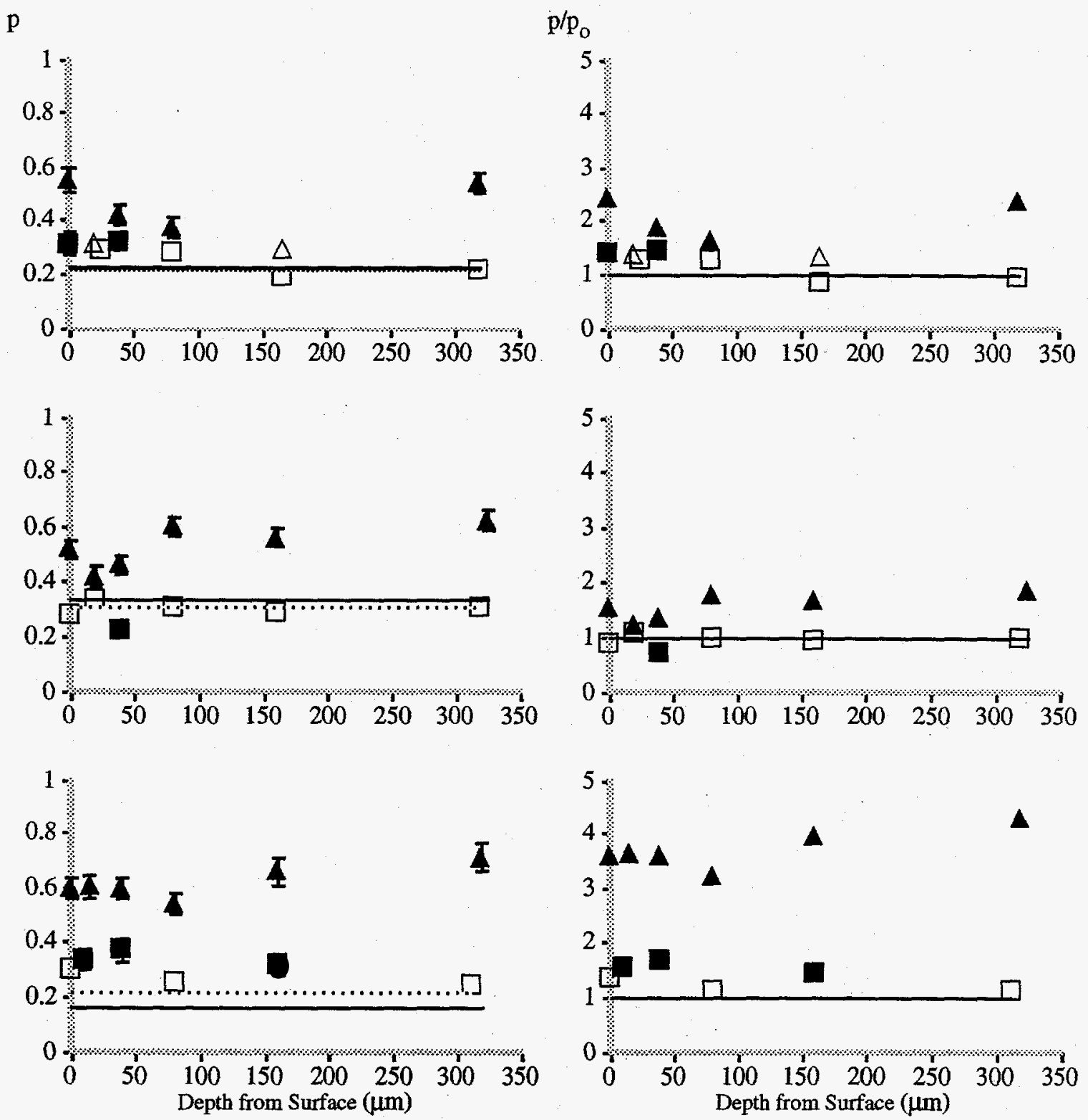

Figure 6 Individual peak analysis of the XRDCD data for AISI304. Comparison of the combined results from the near surface and subsurface for the both the $\Delta \varepsilon=0.60 \%$ and $\Delta \varepsilon=1.20 \%$ regimes at $5 \% \mathrm{~N} / \mathrm{Nf}$ (top), $50 \% \mathrm{~N} / \mathrm{Nf}$ (middle), and failure (bottom). The solid horizontal bars represent the initial state values from the $\Delta \varepsilon=1.20 \%$ regime, and the broken horizontal bars represent the initial state values from the $\Delta \varepsilon=0.60 \%$ regime. ( $(\square) \Delta \varepsilon=0.60 \%$ regime, $\Delta(\Delta) \Delta \varepsilon=1.20 \%$ regime.

The solid symbols represent results which have a statistically significant difference from the initial state; and, the outlined symbols represent results which have no statistically significant difference from the initial state. 

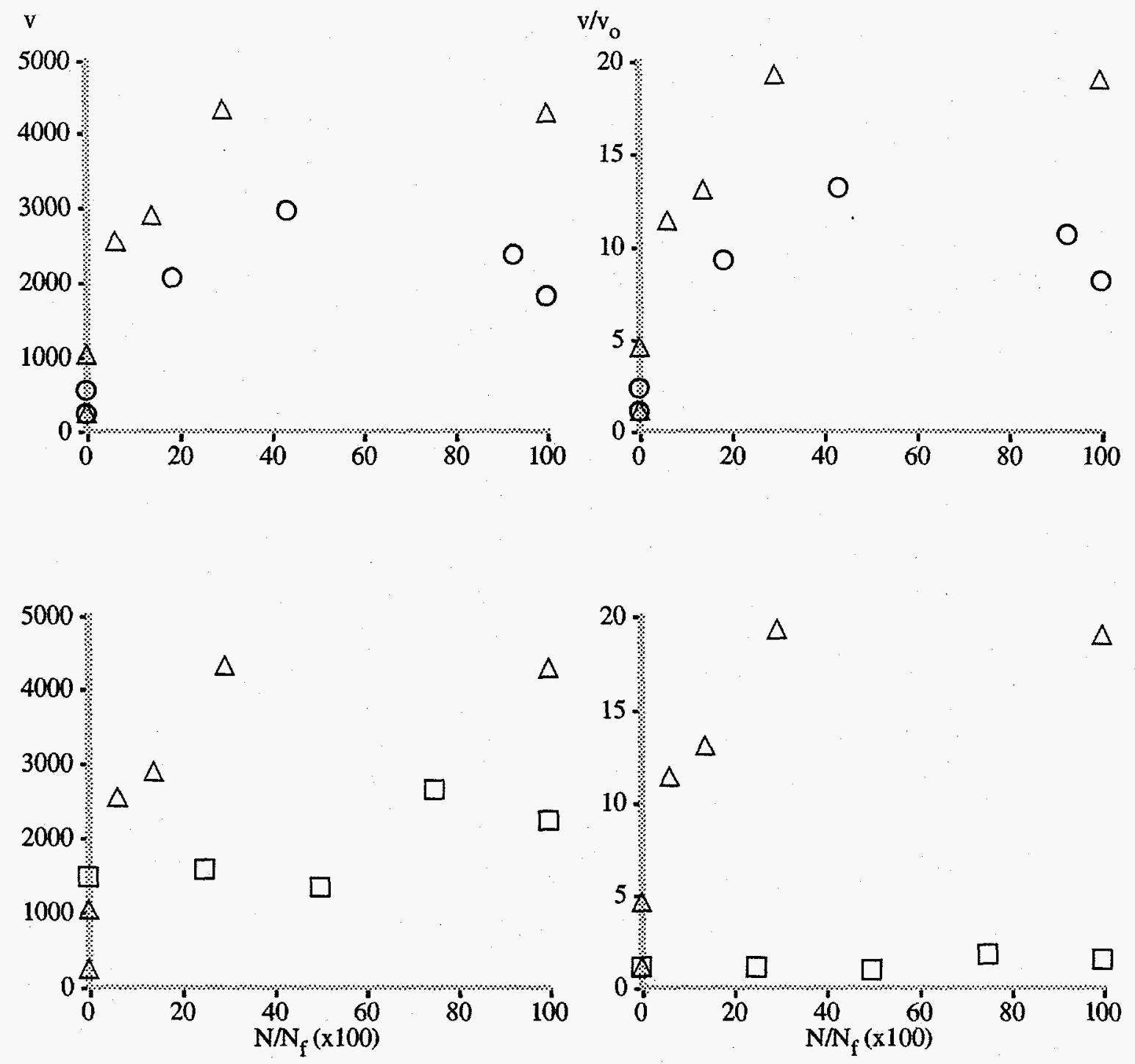

Figure 7 Variance analysis of the XRDCD data for SA508. Comparison of the combined results from the $\Delta \varepsilon=0.48 \%$ and $\Delta \varepsilon=0.78 \%$ regimes (top) and the combined results from near surface and bulk for the $\Delta \varepsilon=0.78 \%$ regime (bottom).

$\circ \Delta \varepsilon=0.48 \%$ near surface, $\Delta \Delta \varepsilon=0.78 \%$ near surface, $\square \Delta \varepsilon=0.78 \%$ bulk. 


\section{DISCUSSION}

The results of this investigation indicate that the XRDCD technique is sensitive to the microstructural deformation caused by fatigue in steels. Therefore, this XRD technique can be used to monitor fatigue damage in steels. The XRDCD data indicate a measurable change from the initial state to subsequent states induced by fatigue of both the fcc material (AISI304) and the bcc material (SA508). For the fcc material, Figures 5 and 6 for the individual peak analysis of the XRDCD data show coherent trends in the results with fatigue damage accumulation or into the depth. For the bcc material, Figure 7 for the variance analysis of the XRDCD data shows coherent trends in the results as the fatigue damage accumulates. A discussion of specific features of the results and the underlying microstructural deformation follows.

For the fcc material, lattice distortion increased as fatigue damage accumulated in the near surface, subsurface, and bulk regions. Figures 5 and 6 show an increase in the integral breadths with fatigue damage. The increase in the integral breadth indicates that the diffraction profiles from the XRDCD data "broadened". The integral breadth is a quantitative measure of the broadening in the diffraction profiles, as shown in Figure 2. Prior to cyclic loading, the annealed, fcc material had a low dislocation density as compared to a cold worked material. During cyclic loading, dislocation regeneration occurred to accommodate the imposed strains. The increase in the dislocation density enhanced the development of the cell dislocation configuration as the dislocations reconfigured into lower energy states. As a result, the X-ray diffraction profiles broadened in general. Furthermore, multimodal peak formation, indicating cell dislocation configurations, is evident in the XRDCD data shown in Figure 2.

Comparison of the results from the near surface and the subsurface shows that the level of lattice distortion increased as the strain amplitude increased. The increase in the integral breadths (Figures 5 and 6) was greater for the material fatigued with a $1.20 \%$ strain range than the material cycled with a $0.60 \%$ strain range. The larger strain amplitude increased the rate of dislocation regeneration. With a higher dislocation density, the development of the cell dislocation configuration is more complete [10]. Therefore, the level of lattice distortion and cell development was greater in the fcc material cycled at the larger strain amplitude.

For the fcc material, the level of lattice distortion was greater in the bulk material than the near surface material. Figure 5 shows a comparison between the near surface and the bulk for the material cycled with a $0.60 \%$ strain range. The change in the integral breadths from the bulk material is greater than the change in the integral breadths from the near surface material. Initially, the free surface both attracts dislocations and allows them to egress, until the increase in the near surface strain energy due to the dislocation density increase begins to repel dislocations rather than attract them $[5,27,28]$. In contrast, no decrease in dislocation density due to egress occurs in the bulk, although mutual annihilation still occurs. Even though the dislocation regeneration rate in the near surface may exceed the bulk because of the decreased dislocation density in the near surface, the regeneration rate in both regions would still be low as compared to a fcc material that cross slips easily. Austenitic stainless steel, such as AISI304, cross slips with difficulty; and, as a result, the dislocation regeneration rate is low. Therefore, the dislocation density in the bulk would remain greater than the density in the near surface, even with dislocation regeneration occurring at a greater rate. With the higher dislocation density, the development of the cell dislocation configuration in the bulk would be more complete. Hence, the broadening of the diffraction profiles and the formation of multimodal profiles would be greater in the bulk as indicated by the results. Similarly, although less apparent, the lattice distortion and the development of cell dislocation configurations were greater in the subsurface than the near surface (Figure 6). 
In contrast to the cyclic microstructural deformation caused by the cyclic loading of the fcc material, the lattice distortion decreased in the bcc material. The increase in the variance parameter indicates that the diffraction profiles from the XRDCD data became increasingly acicular. As for the formation of cell dislocation configurations, the high density of diffraction peaks in the XRDCD data from the bcc material (see Figure 3) preclude distinguishing multimodal peaks that indicate cell dislocation configurations. As a quenched, bainitic steel, the bcc material contains ferrite laths that begin with a high density of randomly oriented dislocations [29]. Although bainite is a multiphase alloy, the XRDCD data was gathered primarily from the ferrite phase, because of the diffraction angle used. The externally applied cyclic loading provides the energy for the dislocations to glide and reconfigure into lower strain energy configurations. During this process, mutual annihilation of dislocations and dislocation egress at the free surface occur. Therefore, the dislocation density decreases; and, as a result, the lattice distortion decreases.

For the bcc material, the decrease in the lattice distortion was greater in the near surface material than in the bulk material, in contrast to the results for the fcc material. Figure 7 shows a comparison between the results from the near surface and the bulk regions for the material cycled with a $0.78 \%$ strain range. The change in the variance estimator from the near surface material is greater than the change in the variance estimator from the bulk material. The variance estimator increased with fatigue damage in both regions. Like the fcc material, dislocation egress at the free surface occurred in the bcc material. However, as a material that cross slips with ease, the bcc material has a greater rate of dislocation regeneration than the fcc material. Therefore, the dislocation density reduction in the near surface of the bcc material due to egress at the free surface was quickly reversed as dislocation regeneration occurred to allow the material to accommodate the imposed strains. With the higher dislocation density, the reconfiguration of the dislocations into lower strain energy states is more complete.

Finally, in the near surface of the bcc material, the magnitude of the lattice distortion change increased as the strain amplitude increased. The increase in the variance parameter ( Figure 7) was greater for the material fatigued at a strain range of $0.78 \%$ than the material cycled with a strain range equal to $0.48 \%$. As the strain amplitude increases, the number of gliding dislocations increase. As a result, dislocation egress at the free surface increases, and subsequent dislocation regeneration is more effective. As already discussed for the fcc material, the reconfiguration of the dislocations into lower strain energy states is more complete as the number of dislocations involved in the cyclic microstructural deformation process increases.

\section{CONCLUSIONS}

The general conclusion of the research presented in this paper is that X-ray double crystal diffractometry (XRDCD) was shown to be sensitive to the microstructural deformation caused by fatigue in steels. Therefore, XRDCD can be used to monitor fatigue damage in steels. This conclusion is significant because assessing fatigue damage with XRDCD had yet to be demonstrated on steels. Specifically referring to the results from Pangborn et al. [30], Allen et al. stated, "It remains to be determined whether such a method [XRDCD] could be applied to steel." [31]. Specific conclusions of the research are summarized as follows:

\section{For the fcc material (AISI304), lattice distortion increased and cell dislocation} configurations developed as fatigue damage accumulated in the near surface, subsurface, and bulk regions. In contrast, the lattice distortion decreased as fatigue damage accumulated in the near surface and bulk regions of the bcc material (SA508). 
2. In both materials, cyclic microstructural deformation increased as the strain amplitude increased.

3. For the fcc material, the level of lattice distortion was greater in the bulk material than the near surface material. In contrast, the level of lattice distortion was greater in the near surface region than the bulk for the bcc material. This conclusion supports previous investigations that also showed a greater microstructural deformation in the near surface than the bulk for bcc Fe alloys $[32,33]$. The results from the fcc material, however, are contrary to the results from previous investigations of near surface deformation in fcc alloys, specifically $\mathrm{Al}$ alloys and $\mathrm{Ni}$ alloys $[14,17]$. The difference is that the austenitic stainless steel (AISI304) cross slips with difficulty. As a result, the cyclic microstructural deformation develops differently in the near surface region.

4. XRDCD was shown to be useful on an engineering material with a complex microstructure, that is the bainitic pressure vessel steel, SA508.

\section{ACKNOWLEDGMENTS}

Ishikawajima-Harima Heavy Industries Company (IHI) provided support, the SA508 test bars, and the samples of both materials used to characterize the bulk.

\section{REFERENCES}

1. Grosskreutz, J.C. Physica Status Solidi (B), 1971. 47: p. 11-31.

2. Grosskreutz, J.C. Physica Status Solidi (B), 1971. 47: p. 359-396.

3. Mughrabi, H., in Surface Effects in Crystal Plasticity, R.M. Latanision and J.T. Fourie, Editors. 1977, Noordhoff International Publishing. p. 479-485.

4. Mughrabi, H., in the Fifth International Conference on the Strength of Metals and Alloys. 1980. Aachen, Federal Republic of Germany. Toronto: Pergamon Press.

5. Mughrabi, H., et al., in Fatigue Mechanisms: Advances in Quantitative Measurement of Physical Damage, ASTM STP 811, J. Lankford, et al., Editors. 1983, ASTM: Philadelphia. p. 5-45.

6. Mughrabi, H., in the Conference to Celebrate the Fiftieth Anniversary of the Concept of Dislocation in Crystals. 1984. London: Institute of Metals.

7. Sudarshan, T.S. and M.R. Louthan, Jr. International Materials Review, 1987. 32(3): p. 121-151.

8. Sudarshan, T.S., T.S. Srivatsan, and D.P. Harvey, II. Engineering Fracture Mechanics, 1990. 36(6): p. 827-852.

9. Laird, C., in Work Hardening in Tension and Fatigue, A.W. Thompson, Editor. 1977, AIME. p. 150-176.

10. Kuhlmann-Wilsdorf, D. Materials Science and Engineering, 1989. A113: p. 1-41.

11. Pangborn, R.N. and B.L. Peterson. Crystal Properties and Preparation, 1988. 16: p. $185-200$.

12. Mayo, W.E. International Journal of Fatigue, 1987. 9(4): p. 203-209.

13. Mayo, W.E. and S. Weissmann, in Microstructural Characterization of Materials by Non-Microscopical Techniques, N.H. Andersen, et al., Editors. 1984, Ris $\emptyset$ National Laboratory: Roskilde, Denmark. p. 391-396.

14. Khatri, R.P., et al. Journal of Materials Science, 1986. 21: p. 511-521. 
15. Mayo, W.E. and S. Weissmann, in The Second International Conference on Fatigue and Fatigue Thresholds. 1984. Birmingham, England: Engineering Materials Advisory Services Ltd.

16. Pangborn, R.N., S. Weissmann, and I.R. Kramer. Advances in X-Ray Analysis, 1981. 24: p. 203-208.

17. Pangborn, R.N., S. Weissmann, and I.R. Kramer. Metallurgical Transactions A, 1981. 12A: p. 109-120.

18. Pangborn, R.N., S. Weissmann, and I.R. Kramer. Scripta Metallurgica, 1978. 12(2): p. 129-131.

19. Zamrik, S.Y. and R.N. Pangborn. Nuclear Engineering and Design, 1989. 116: p. 407-413.

20. Weiss, V. and Y. Oshida, in The Second International Conference on Fatigue and Fatigue Thresholds. 1984. Birmingham, England: Engineering Materials Advisory Services Ltd.

21. Field, J.L., F. Behnaz, and R.N. Pangborn, in Fatigue Mechanisms: Advances in Quantitative Measurment of Physical Damage, ASTM STP 811, J. Lankford, et al.; Editors. 1983, ASTM: Philadelphia. p. 71-94.

22. Evans, W.P., R.E. Ricklefs, and J.F. Millan, in Local Atomic Arrangements Studied by X-Ray Diffraction, J.B. Cohen and J.E. Hilliard, Editors. 1966, Gordon and Breach, Science Publishers, Inc: New York. p. 351-377.

23. Taira, S. and K. Honda. Bulletin of JSME, 1961. 4(14): p. 230-237.

24. Nakagawa, H., H. Yoshizawa, and M.E. Lapides. Metallurgical Transactions A, 1990. 21A: p. 1989-1996.

25. Pangborn, R.N., Surface Layer and Bulk Plasticity of Tensile Deformed and Fatigue Cycled Metals and Prediction of Fatigue Life by X-ray Diffraction. Ph.D. 1979, Rutgers University, The State University of New Jersey (New Brunswick).

26. Devore, J.L., Probability and Statistics for Engineering and the Sciences. 3rd ed. 1991, Monterey, California: Brooks/Cole Publishing Company. 716.

27. Hull, D. and D.J. Bacon, Introduction to Dislocations. 3rd ed. International Series on Materials Science and Technology. Vol. 37. 1984, Oxford: Pergamon Press. 255.

28. Jastrzebski, Z.D., The Nature and Properties of Engineering Materials. 2nd ed. 1976: John Wiley \& Sons, Inc.

29. Edmonds, D.V. and R.C. Cochrane. Metallurgical Transactions A, 1990. 21A: p. 1527-1539.

30. Pangborn, R.N., S. Weissmann, and I.R. Kramer, in Strength of Metals and Alloys, Proceedings of the Fifth International Conference. 1979.

31. Allen, A.J., et al., Microstructural Examination of Fatigue Accumulation in Critical LWR Components. Final Report for Electric Power Research Institute. No. NP5590. January 1988, United Kingdom Atomic Energy Authority.

32. Kramer, I.R., in Advances in the Mechanics and Physics of Surfaces, R.M. Latanision and T.E. Fischer, Editors. 1986, Harwood Academic Publishers: Chur, Switzerland. p. 109-248.

33. Lee, W.J., Y.W. Chung, and M.E. Fine. Metallurgical Transactions A, 1988. 19A: p. 337-344. 